\title{
CULTIVO PROTEGIDO DE VIDEIRA: MANEJO FITOSSANITÁRIO, QUALIDADE ENOLÓGICA E IMPACTO AMBIENTAL ${ }^{1}$
}

\author{
GERALDO CHAVARRIA² \& HENRIQUE PESSOA DOS SANTOS 3
}

RESUMO - O cultivo protegido na cultura da videira apresenta-se como uma alternativa na diminuição da incidência de doenças fúngicas em regiões que apresentam excesso de chuvas. A utilização de cobertura plástica sobre as linhas de cultivo da videira ocasiona modificações no microclima ao redor da planta, principalmente pela ausência de água livre sobre folhas e frutos. Estas alterações propiciam condições desfavoráveis ao desenvolvimento de doenças fúngicas, com a menor necessidade do uso de fungicidas, como as podridões de cachos, que atualmente são um dos maiores problemas no controle fitossanitário, em regiões produtoras tradicionais, como a Serra Gaúcha. Todavia, o oídio da videira que outrora não apresentava incidência em condições de alta umidade relativa, em condições de cultivo protegido, deve ser monitorado. Outro aspecto que merece cautela é o uso de fungicidas, pois destaca-se que, pela redução de radiação ultravioleta e ausência de chuvas sobre os cachos, devido ao uso da cobertura plástica, o período residual dos fungicidas é prolongado. Este maior acúmulo é preocupante, tanto nas uvas destinadas ao consumo in natura, que afeta diretamente o consumidor, quanto às destinadas à vinificação, que prejudica a atuação das leveduras na fermentação dos vinhos. De forma geral, a tecnologia de cobrimento dos vinhedos é eficaz no controle de doenças fúngicas e na redução do uso de fungicidas, contudo deve ser considerada como um novo sistema de produção, principalmente por exigir um manejo fitossanitário distinto em relação ao cultivo convencional. Os plásticos de cobertura, usados, devem ser considerados resíduo agrícola, exigindo cuidados específicos para que seja evitada contaminação ambiental.

Termos para indexação: plasticultura, videira, água livre, doenças fúngicas, resíduos.

\section{PROTECTED CULTIVATION OF GRAPEVINE: DISEASE MANAGEMENT, ENOLOGICAL QUALITY, AND ENVIRONMENTAL IMPACT}

\begin{abstract}
The protected cultivation of grapes is an alternative to reduce the incidence of fungal diseases in regions with excess rainfall. The use of plastic covering on vine planting rows produces changes in the microclimate around the plant, due mainly to the absence of freely available water on leaves and berries. These changes hinder the development of fungal diseases, such as bunch rot - currently one of the biggest challenges in disease control in traditional grape growing regions like Serra Gaúcha - and reduce fungicide use. However, powdery mildew, whose incidence under high relative humidity conditions is usually low, must be closely monitored in protected cultivation. Also, fungicides must be used with caution as plastic covering reduces the incidence of ultraviolet radiation and rainfall on clusters, thereby increasing the residual effect of fungicides. The higher accumulation of fungicide on grapes directly affects their in natura consumption and compromises yeast fermentation during the winemaking process. In general, plastic covering is efficient in controlling fungal diseases and in reducing fungicide use, but it must be regarded as a new cultivation system as it requires distinct disease control compared to conventional cultivation. The used plastic covering must be regarded as crop residues, demanding specific precautions against environmental contamination. Index terms: plasticulture, grapevine, freely available water, fungal diseases, residues.
\end{abstract}

\footnotetext{
'(Trabalho 129-13). Recebido em: 15-03-2013. Aceito para publicação em: 10-09-2013.

${ }^{2}$ Eng. Agr ${ }^{\circ}$ Dr. Professor Fisiologia das Plantas Cultivadas, Universidade de Passo Fundo, CEP 99001-970, Passo Fundo-RS. E-mail: geraldochavarria@upf.br

${ }^{3}$ Eng. Agr ${ }^{\circ}$ Dr. Pesquisador Embrapa Uva e Vinho, CEP 95700-000, Bento Gonçalves-RS. E-mail: henrique.p.santos@embrapa.br
} 


\section{INTRODUÇÃO}

A viticultura mundial destinada à vinificação está sobretudo concentrada entre os paralelos $30^{\circ} \mathrm{e}$ $50^{\circ}$ de latitude norte e entre $30^{\circ}$ e $45^{\circ}$ de latitude sul, onde os principais climas são do tipo temperado, mediterrâneo ou árido, em diferentes níveis. No Brasil, os tipos de clima ocorrentes nas regiões vitivinícolas produtoras de vinhos finos com uma colheita anual são de tipo temperado e subtropical (TONIETTO; MANDELLI, 2003). Basicamente, a vitivinicultura brasileira situa-se nos Estados do Rio Grande do Sul, Santa Catarina, Paraná, São Paulo, Minas Gerais, Bahia e Pernambuco. Em 2012, o País possuía cerca de 90 mil hectares, tendo nesta safra uma colheita de 1.455.809 t de uvas (IBGE, 2013). Em 2011, foram exportadas 59,4 mil toneladas de frutas in natura, 4,5 mil toneladas de suco, 1,2 milhão de litros de vinho e 112 mil litros de espumante (IBGE, 2013). Contudo, em relação às uvas na forma de passas, $\mathrm{o}$ Brasil é totalmente dependente do mercado externo, onde no ano de 2006 foram sendo importadas 24,3 mil toneladas de uvas passificadas (IBGE, 2013), no ano de 2006.

O Estado do Rio Grande do Sul é responsável por mais de $50 \%$ da produção de uva e por $90 \%$ da produção nacional de vinhos e derivados (IBGE, 2013). Atualmente, existem seis regiões vitivinícolas no Estado: Campanha (Bagé e Santana do Livramento), Serra do Sudeste (Pinheiro Machado e Encruzilhada do Sul), Jaguari (Jaguari), São José do Ouro (São José do Ouro), Rolante (Rolante e Riozinho) e a Encosta Superior do Nordeste conhecida como "Serra Gaúcha". Nesta última região, podem ocorrer algumas condições climáticas que são desfavoráveis ao cultivo de videira. Conhecidamente, a frequência e a distribuição de chuvas são elementos climáticos de grande importância neste processo produtivo, sendo que, nesta região Sul do Brasil, há uma série histórica pluviométrica com tendência ao excesso no período de maturação e colheita, se comparada a regiões vitícolas tradicionais de outros países (MOTA et al., 2008; CHAVARRIA et al., 2010).

Devido a estas características climáticas, é observada com frequência a realização de colheitas antecipadas, em comparação ao ponto ideal de maturação. Esta prática tem sido realizada com o intuito de evitar perdas ocasionadas por podridões dos frutos, porém resulta no comprometimento da qualidade da uva e do mosto pela paralisação do processo de maturação (LULU et al., 2005; CHAVARRIA et al., 2010; COLOMBO et al., 2011).

Desde o aparecimento da indústria petroquímica na década de 30 , e, com o crescimento da utilização do plástico em diversos setores, a partir da Segunda Grande Guerra, o setor agrícola começou a utilizar este material em diferentes campos de aplicação. O plástico tem sido empregado nas atividades agropecuárias com maior participação na produção de alimentos, substituindo materiais tradicionais, como madeira, vidro, ferro e cimento, com a finalidade de minimizar os custos de produção e inovar técnicas tradicionais, para se obter aumento de produtividade. Dessa forma, a plasticultura pode ser definida como a técnica da aplicação dos materiais plásticos na agricultura (ESPÍ et al., 2006, CASTELLANO et al., 2008).

O cultivo protegido tem sido um importante insumo agrícola que permite incrementos de produção das culturas, onde se esgotaram as tentativas convencionais para obterem-se incrementos produtivos. Nesse novo ambiente de cultivo, as plantas são postas sob um novo limite de produtividade, visando a propiciar condições para a expressão de seu máximo potencial genético. Nesta circunstância, o manejo inadequado da planta e do solo pode possibilitar condições muito favoráveis a determinadas doenças bióticas ou abióticas. Assim, doenças menos problemáticas ou de pouca importância em cultivo convencional podem apresentar maior severidade em cultivo protegido (VIDA et al., 2004).

Segundo Mota et al. (2009), a utilização de cobertura plástica em vinhedos vem tomando maiores proporções em área. $\mathrm{O}$ autor destaca que atualmente existe área aproximada de 700; 80 e 70 hectares, respectivamente, na região Nordeste do Brasil, e nos Estados do Rio Grande do Sul e Santa Catarina. Nestas áreas protegidas, predomina o cultivo de Vitis vinifera destinada ao consumo in natura. No Rio Grande do Sul, onde teve seu início na região de Ivoti, na década de 70 , por uma colônia japonesa, o uso de cobertura plástica sobre as linhas de cultivo está presente atualmente em maior proporção na região de Caxias do Sul, onde existe um polo de produção de uvas de mesa (SANTOS; CHAVARRIA, 2012). Contudo, o uso desta tecnologia é incipiente em uvas destinadas à vinificação.

De maneira geral, o conhecimento dos efeitos desta tecnologia sobre a incidência e a necessidade de controle de doenças fúngicas, resíduos de agroquímicos, influências sobre a qualidade enológica e os riscos desta atividade sobre o ambiente são bastante recentes, e esta revisão de literatura propõe-se a apresentar informações sobre estas temáticas. 


\section{Incidência de doenças fúngicas e necessidade de controle}

No cultivo convencional a céu aberto de uvas Vitis vinifera no Rio Grande do Sul, são realizadas, em média, 14 pulverizações com fungicidas (SANTOS; CHAVARRIA; 2012), sendo que 8 a 10 são efetuadas para o controle do míldio (Plasmopara viticola) (MENDES, 2002). Existem regiões do Brasil, como no Estado do Paraná, onde são realizadas até 60 aplicações em uvas Vitis vinifera durante os dois ciclos ocorridos por ano. Em diversas regiões do Brasil, de forma corrente, os produtores realizam pulverizações semanais (método por calendário) com a intenção de garantir a produção e, muitas vezes, sem a real necessidade de aplicação de fungicidas.

Neste contexto, o ambiente protegido pode representar uma alternativa viável para minimizar problemas com a maturação das uvas e de manejo fitossanitário, principalmente por possibilitar modificações no microclima (CHAVARRIA et al., 2009a; CARDOSO et al., 2010). Nestas condições, destaca-se a possibilidade de restrição da água livre sobre as folhas e frutos, que é o fator primário e principal para desencadear o início das infecções fúngicas na videira (LAFON ; CLERJEAU, 1988). O uso de cobertura plástica pode ser considerado o mais recente insumo agrícola, visando ao incremento da produção e da qualidade, onde técnicas convencionais já foram esgotadas (ARAÚJO; CASTELLANE, 1996).

Com a utilização da cobertura plástica, existe a tendência de redução do uso de agrotóxicos. Isto foi comprovado por Chavarria et al. (2007b), de forma que foram necessárias apenas duas aplicações para o controle do oídio na área coberta, durante o primeiro ciclo do experimento. Em contrapartida, no mesmo ciclo, foram realizadas 17 aplicações para o controle de doenças fúngicas no cultivo convencional. Contudo, no segundo ciclo, não foi utilizado nenhum fungicida na área com cobertura plástica, ao passo que no cultivo convencional, foram realizadas 15 aplicações. Salienta-se que, pelas condições microclimáticas abaixo da cobertura, as duas aplicações realizadas no primeiro ciclo para oídio foram feitas apenas nos focos de ocorrência e não em toda a área, com total eficácia de controle. Desta forma, nos dois anos avaliados, além da diminuição dos gastos com fungicidas na área coberta, tanto o produtor como o ambiente tiveram uma redução de aproximadamente 15 vezes no nível de exposição e de contaminação por estes produtos, o que pode viabilizar a produção orgânica de uvas
(CHAVARRIA et al., 2007a).

Avaliando a incidência de doenças fúngicas (\% de cachos infectados e \% de bagas infetadas por cacho) na cultivar Moscato Giallo sob cobertura plástica, em dois anos, Chavarria et al. (2007a; 2007b) observaram uma diminuição significativa na incidência de podridões de cacho nos dois ciclos estudados, em relação ao cultivo sem cobertura, atingindo, em média, $64,09 \%$ e $32,62 \%$, respectivamente, para os ciclos de 2005/2006 e 2006/2007. Neste percentual de redução de incidência de doenças, respectivamente nos dois ciclos, destacaram-se principalmente, a podridão-da-uva-madura $(79,71 \%$ e $53,03 \%)$ e a podridão ácida $(73,18 \%$ e $45,56 \%)$. As podridões de cacho consistem em um grande problema na viabilidade da produção vitícola por não existirem, ainda, medidas de controle inteiramente eficazes. Desta forma, os resultados obtidos com a cobertura plástica apontam para uma possibilidade de controle e sem o ônus da contaminação, pois este ocorre pela mudança microclimática e não pelo emprego de agroquímicos. Corroborando este ponto de vista, destacam-se os resultados obtidos por Botelho et al. (2011) sobre a viabilidade do cultivo protegido como uma alternativa para a produção de vinhos tintos orgânicos.

Quanto à incidência de bagas infetadas por cacho, com o uso da cobertura, também houve decréscimo significativo em podridão-da-uvamadura de $87,43 \%$ e $94,29 \%$, em podridão-cinzentada-uva de $57,64 \%$ e $56,03 \%$, e de podridão ácida de $84,48 \%$ e $83,69 \%$, respectivamente, nas safras 2006 e 2007 (CHAVARRIA et al., 2009a). Santos e Chavarria (2012) também observaram redução na incidência de bagas infetadas por cacho nas cultivares Cabernet Sauvignon, Moscato Giallo e Riesling Itálico, havendo apenas alguns focos de oídio e podridão ácida no ambiente protegido, próximo ao ponto de colheita, os quais não comprometeram a qualidade enológica da uva.

Em relação à dispersão de esporos de fungos em ambiente protegido, Chavarria et al. (2009b) observaram que a quantidade média diária de esporangiósporos de Plasmopara viticola capturada sob cobertura plástica foi significativamente superior, em relação ao cultivo convencional. Embora não tenha sido verificada diferença significativa entre os tratamentos nos ciclos de 2005/2006 e 2006/2007, o autores observaram uma tendência considerável de maiores médias diárias. Contudo, levando em consideração média horária, a área coberta apresentou quantidades significativamente superiores de esporangiósporos em relação à área descoberta, nos dois ciclos avaliados. Considerando este fato, 
de que a cobertura plástica não inibe a presença dos esporos, mas restringe a incidência de míldio da videira (CHAVARRIA et al., 2007b), é possível afirmar que o principal fator que impede a presença desta doença são as condições microclimáticas desfavoráveis sob as coberturas.

Conforme salientado anteriormente, a umidade relativa do ar não apresenta diferença entre ambientes protegidos e convencionais. Sendo assim, esta variável não se apresenta como o fator determinante da ausência de doenças fúngicas em áreas sob coberturas plásticas. Este argumento, aparentemente, representa uma contradição, pois a literatura destaca que a umidade relativa pode propiciar condições para o estabelecimento de doenças fúngicas (GENTA et al., 2010). Estas condições, entretanto, estão relacionadas principalmente com a presença de água livre sobre as partes vegetativas e reprodutivas da planta, que é nula nestes ambientes protegidos (CHAVARRIA et al., 2009a). Na área coberta, a água livre ocorre apenas como condensação na superfície interna dos plásticos, mas sem atingir a vegetação. Diversos modelos apontam que a duração do molhamento foliar, associado à temperatura, atua como fator fundamental para o processo de eficiência da infecção de doenças, como o míldio da videira (LALANCETE et al., 1987). Com água livre disponível, vários processos relacionados às infecções das doenças, incluindo a liberação e a germinação de esporos, penetração do tubo germinativo de fungos e a multiplicação de células de fitobactérias, ficam apenas dependentes da temperatura para seu estabelecimento (SAUTOUR et al., 2001). Deste modo, considerando que na área coberta o fator água não está presente, as condições de infecção das doenças fúngicas são dificultadas. Como exemplo disto, Chavarria et al. (2007b) demonstraram que alguns ramos que saíram para o ambiente externo apresentaram incidência de míldio, ao passo que os mantidos sob cobertura não apresentaram doenças, demonstrando assim o efeito do microclima da cobertura sobre a ocorrência das doenças fúngicas. Apesar destas evidências, em áreas com coberturas plásticas, ainda pode ocorrer o acúmulo de água livre na superfície das folhas pela condensação do vapor de água da atmosfera ou, ainda, ser acumulada pela gutação (exsudação de água pelas bordas foliares, através dos hidatódios), sendo estes fenômenos dependentes das condições de temperatura e de umidade do ar (VIDA et al., 2004). Entretanto, Chavarria et al. (2009a) observaram maior presença de água livre apenas na face interna dos plásticos de cobertura, sendo muito baixa a frequência de gutação.

A água no cultivo sob cobertura plástica fica retida por um período superior, pelo fato de o microclima sob a cobertura apresentar menor déficit de pressão de vapor (DPV) e velocidade do vento (RANA et al., 2004). Deste modo, deve-se considerar a necessidade de evitar ao máximo a entrada de água neste sistema, haja vista esta dificuldade de evaporação que pode propiciar condições para o estabelecimento de doenças. Este controle de entrada de água pode ser obtido através de alterações na estrutura de sustentação dos plásticos ou no controle da irrigação.

A cobertura plástica reduz a radiação solar e, segundo Cañizares (1998), a redução da luminosidade favorece a incidência de oídio (Uncinula necator). Com isto, o sombreamento, associado às condições de restrição hídrica e à elevação das temperaturas ocasionadas pelas coberturas plásticas, pode favorecer o surgimento deste fungo (GRIGOLETTI JÚNIOR;SÔNEGO, 1993)

\section{Resíduos de fungicidas}

Considerando as variações microclimáticas impostas pela cobertura, destaca-se que, além da influência sobre o estabelecimento de doenças, podem também ocorrer alterações na eficácia do controle químico. Isto porque este é bastante influenciável pelos elementos climáticos, como temperatura, precipitação e umidade relativa do ar, principalmente no período de crescimento das brotações (CZERMAINSKI;SÔNEGO, 2004). Por desconhecerem o manejo fitossanitário adequado no cultivo protegido, alguns produtores realizam aplicações recomendadas para o cultivo convencional como se estivessem cultivando a céu aberto. Todavia, deve ser salientado que o cultivo protegido se apresenta como um agrossistema diferenciado, e os produtos aplicados podem apresentar um período residual também diferenciado em relação ao cultivo convencional. Em cultivo protegido de tomate, Frank et al. (1987) demonstraram que ocorre um incremento no período residual (carência) dos fungicidas, atingindo concentrações de 10 a 20 vezes maiores dos fungicidas captan e clorotalonil.

Para comprovar esta persistência de fungicidas em vinhedos sob coberturas plásticas, Chavarria et al. (2007b) analisaram o acúmulo residual do princípio ativo captan. Neste estudo, verificou-se o incremento de $18,26 \%$ no resíduo de captan nos cachos cultivados sob cobertura plástica, na avaliação realizada aos dois dias após a primeira aplicação, e $33,1 \%$ e $27,52 \%$, nas avaliações realizadas dois e sete dias após a segunda aplicação, respectivamente. Este efeito residual aumenta a ação dos produtos no controle fitossanitário, mas também pode influenciar 
negativamente na vinificação, já que as leveduras responsáveis pelo processo fermentativo são fungos. Ressalta-se, também, que esse aumento de resíduos, se não considerar alterações no manejo fitossanitário, pode ocorrer em uvas de mesa in natura e causar problemas à saúde dos consumidores.

O prolongamento da atividade/resíduo dos produtos está, possivelmente, relacionado a dois fatores originados pela alteração do microclima devido ao uso de cobertura plástica: a restrição de molhamento e de radiação solar. A chuva tem um efeito direto na lixiviação do produto aplicado e, se esta não ocorre, principalmente lavando os cachos e folhas, o efeito residual é prolongado. Este efeito já foi observado em cafeeiro, onde foi verificada a baixa persistência de mancozeb sob condições de chuva induzida (SANTOS et al., 2002). A diminuição da incidência de radiação solar ocasionada pela cobertura plástica também afeta a persistência dos fungicidas (FRANK et al., 1987). Os plásticos utilizados nas coberturas possuem aditivos químicos bloqueadores de raios ultravioleta, para aumentar sua durabilidade a campo (SANTOS; CHAVARRIA, 2012). Entretanto, este bloqueio pode impedir a degradação das moléculas de fungicidas, o que aumenta a persistência dos produtos nas condições de cultivo protegido.

Considerando, em conjunto, as condições microclimáticas proporcionadas pela cobertura plástica contrárias ao estabelecimento de doenças e esta maior persistência dos fungicidas aplicados, destaca-se a redução na necessidade de pulverizações. Com isso, consequentemente, restringe-se a possibilidade de ocorrência de resistência nos patógenos aos produtos fitossanitários. Esta ocorrência tem sido observada com frequência no cultivo convencional de videira e, em muitos casos, levando a um incremento no número de aplicações e na demanda por novos princípios ativos (GRIGOLETTI JÚNIOR;SÔNEGO, 1993). Além desse enfoque, estudos com a utilização de produtos alternativos em áreas de cultivo protegido, como leite e bicarbonato de sódio para o controle do oídio em algumas culturas, têm demonstrado resultados promissores (ZANTARIM et al., 2005).

\section{Interferência na qualidade enológica}

A sanidade das uvas é outro aspecto importante na definição da qualidade dos vinhos, e se trata de um entrave na produção de vinhos finos de qualidade na região da "Serra Gaúcha" (SANTOS; CHAVARRIA, 2012). Algumas doenças fúngicas, além de prejudicarem a produção das uvas propriamente, afetam a qualidade dos vinhos durante o processo de vinificação e envelhecimento. Uvas com Botrytis cinerea, por exemplo, contêm maiores concentrações de tirosinase e lacase, que são enzimas responsáveis pela oxidação enzimática dos compostos fenólicos, prejudicando a cor, o aroma e o sabor dos vinhos (SÔNEGO et al., 2005).

A restrição de radiação solar imposta pela cobertura plástica (RANA et al., 2004) não influencia, na maioria das vezes, o conteúdo de açúcares nas bagas, como foi observado por Detoni et al. (2007) na cultivar Cabernet Sauvignon. Contudo, os autores observaram maiores valores de acidez total titulável e $\mathrm{pH}$ nestas condições.

A acidez do mosto da uva, composta majoritariamente pelos ácidos tartárico e málico (BLOUIN; GUIMBERTEAU, 2000), pode ser influenciada pela cobertura plástica, independentemente de fatores fitossanitários. Haja vista que o incremento da temperatura sob o plástico aumenta a atividade respiratória e o consumo de ácidos orgânicos.

Porém, quando comparasse a acidez volátil dos vinhos de videiras cultivadas sob cobertura plástica algumas diferenças são observadas, Chavarria et al. (2011) observaram que os valores de acidez volátil do vinho da cultivar Moscato Giallo foram de 3,3 e 8,0 meq. $L^{-1}$ na safra de 2006 para as áreas coberta e descoberta, respectivamente. Estes menores valores de acidez volátil alcançados no vinho da área coberta estão associados à maior sanidade das uvas, as quais apresentaram menor incidência e severidade de podridões de cacho, sobretudo de podridão ácida, que é a principal causadora deste defeito no vinho (CHAVARRIA et al., 2007b). Isto também foi comprovado pela significativa redução de acetato de etila no vinho da área coberta, nas três safras, em relação à descoberta. Tanto a acidez volátil quanto o acetato de etila são marcados, nos vinhos da sanidade das uvas, valores mais elevados, denotando defeitos nos vinhos, perceptíveis sensorialmente, através de odor indesejável e amargor (CHAVARRIA et al., 2011).

A coloração do vinho, analisada pelo índice 420, que é a absorbância neste comprimento de onda, trata-se de outro parâmetro de avaliação de oxidações oriundas de podridões de cachos. Chavarria et al. (2011) observaram que este índice foi menor nos vinhos sob cobertura plástica, indicando que estes apresentaram menor intensidade de cor amarela. Isto demonstra que estes vinhos apresentaram menor quantidade de oxidações, possivelmente devido à sanidade das uvas. Desta forma, mesmo vinhos brancos e jovens, produzidos com uvas com 
maiores quantidades de podridões de cacho, poderão apresentar um I 420 mais elevado (MENEGUZZO et al., 2006).

Porém, quando se trata da característica coloração do vinho, quando esta é dependente de biossíntese de compostos na baga e não pela sanidade, a cobertura plástica pode influenciar negativamente na qualidade enológica. Antocianinas podem ser reduzidas em até 34\% (DETONI et al., 2007).

A melhor condição fitossanitária, propiciada pela cobertura, é importante, sobretudo para as uvas brancas, como a cultivar Moscato Giallo, as quais apresentam maior suscetibilidade às podridões de cachos (CHAVARRIA et al., 2007b). Sendo assim, a melhoria da sanidade das uvas destaca-se como uma das grandes contribuições que o cultivo de videiras sob cobertura plástica possa propiciar. Sob o ponto de vista técnico, é uma alternativa na busca do incremento da qualidade dos vinhos em regiões que apresentam excesso de chuvas no período da maturação, exemplificada pela "Serra Gaúcha".

\section{O cultivo protegido e o ambiente}

A maioria dos plásticos agrícolas são produzidos a partir de petróleo, geralmente de polietileno, e são causas potenciais de problemas ambientais (HALLEY et al., 2001). Portanto, um ponto importante para o emprego sustentável das coberturas de plástico é o destino do filme de plástico após sua utilização ou vida útil. Isto é importante para se evitar problemas de poluição ambiental com plásticos que podem persistir por séculos (ALBERTSSON et al., 1987).

O plástico destinado à cobertura de videira, assim como para qualquer outro tipo de cultivo protegido, deve ser quimicamente aditivado para apresentar resistência e durabilidade em condições de campo (KASIRAJAN; NGOUAJIO, 2012). Dentre os aditivos mais empregados em plásticos de cobertura, destacam-se aqueles para proteção contra raios ultravioleta (antiUV) e para romper a tensão superficial da água (antigotejamento) (SANTOS; CHAVARRIA, 2012). Destes, os aditivos antiUV são essenciais para evitar a fotooxidação e, consequentemente, o rompimento das fibras do plástico (EDSER, 2002), o que restringe drasticamente a vida útil das coberturas. Apesar do grande avanço na indústria química com o desenvolvimento de aditivos específicos, ainda existe uma grande carência de pesquisas em aditivos para proporcionar maior resistência dos plásticos para o uso agrícola. No aspecto prático, os polietilenos apresentam grande suscetibilidade à oxidação imposta por metais (YU et al., 2000). Portanto, além dos riscos de resíduo na fruta abordado anteriormente, a vida útil das coberturas também se torna sensível aos tratamentos fitossanitários que são realizados na área protegida.

Diante deste cenário, impõe-se um grande dilema para as indústrias de plástico agrícola: 1) aumentar a resistência dos plásticos, exigindo a necessidade de investimentos em reciclagem; ou 2) produzir também aditivos para a implantar uma degradação programada dos plásticos de cobertura, facilitando a degradação após o uso. $\mathrm{Na}$ indústria de plásticos destinados ao 'mulching', tem ocorrido grandes investimentos na obtenção de plásticos biodegradáveis (BONORA; DE CORTE, 2003; KASIRAJAN; NGOUAJIO, 2012). Contudo, na indústria de plásticos destinados à cobertura de cultivos, há um maior interesse em incrementos de durabilidade e qualidade da transparência (EDSER, 2002) em detrimento da biodegradação, considerando que, ao contrário do mulching, há maior necessidade de manter a transparência das coberturas para não comprometer a produção (SANTOS;CHAVARRIA, 2012). Aliado a isso, destaca-se que os plásticos usados na cobertura de videiras, pelo maior tempo de uso (mínimo quatro anos), dispõem de contaminações por tratamentos fitossanitários. Neste caso, estas coberturas deveriam ser enquadradas dentro das mesmas responsabilidades e competências legais das embalagens vazias de agrotóxicos, estabelecidas na Lei Federal no 7.802/1989 e cuja regulamentação foi definida pelo Decreto Federal $n^{\circ}$ 4.074/2002. Contudo, até o presente momento, não há nenhuma regulamentação específica para esse tipo de plástico agrícola.

Diante deste cenário, uma das alternativas para o destino dos plásticos de cobertura que as empresas fabricantes poderiam adotar, seria a reciclagem, dentro da mesma finalidade agrícola ou para outros fins, em analogia às ações de reciclagem de embalagens de agrotóxicos (INPEV, 2012). A adoção desta prática poderia solucionar o risco ambiental do cultivo protegido, podendo os plásticos usados servirem de produto de troca na instalação de novas coberturas, o que reduziria, também, os custos para a manutenção dos cultivos protegidos. 


\section{CONCLUSÕES}

O fator de maior relevância e que pode levar os produtores a investirem nesta tecnologia é o aspecto fitossanitário, onde ocorrem ganhos de qualidade das frutas com drástica redução de agrotóxicos. Outro fator que deve ser bastante enfatizado é a possibilidade de o cultivo protegido ser uma ferramenta para a viabilização de cultivos orgânicos, já que é possível eliminar as aplicações de fungicidas, se a cobertura eliminar a água livre sobre as folhas e cachos. Contudo, apesar deste novo horizonte, um problema sério de saúde pública é enfatizado nesta revisão de literatura, relacionado ao período residual dos produtos fitossanitários. Destacou-se que as frutas cultivadas em condições protegidas podem ter uma quantidade mais elevada de resíduo, se comparado ao cultivo convencional, sem cobertura. Portanto, é oportuno enfatizar que os produtores que realizam aplicações da mesma forma ou às vezes em maior número, buscando uma "proteção" aos seus frutos sem desconhecer os efetivos benefícios do cultivo protegido no aspecto que tange ao manejo fitossanitário, estão elevando, desnecessariamente, o custo de produção e o risco à saúde dos consumidores, e o processo de fermentação em uvas destinadas à vinificação.

Tendo como objetivo a produção de uvas destinadas à vinificação, tecnologia de cobrimento pode ter retorno econômico em situações em que os vitivinicultores realizem as próprias vinificações. Desta maneira, há a possibilidade de elaborar vinhos diferenciados e obter lucro com este diferencial. Pois, quando há repasse destas uvas para grandes vinícolas, na maioria das vezes, não há recompensa pelo incremento em qualidade. Considerando as uvas tintas, o cultivo protegido pode não ser recomendável em função da redução da síntese de compostos que incrementam a qualidade enológica, como antocianinas, em função da redução da radiação solar. Porém, há de se considerar exceções, em regiões onde o fator de maior relevância na obtenção de qualidade enológica seja a incidência de doenças e seu efeito negativo sobre o vinho, como acidez volátil alta, o que se sobressai a parâmetros de qualidade.

Contudo, deve-se observar que a utilização da cobertura plástica na viticultura se apresenta como um novo sistema de cultivo, o qual auxilia no controle de doenças fúngicas e incrementa a produção e a qualidade do produto final, mas que necessita de manejo diferenciado, desde a planta até os produtos utilizados. Além disso, para que essa forma de cultivo tenha sustentabilidade ambiental, os plásticos de cobertura usados devem ser manejados como um resíduo agrícola, exigindo cuidados específicos para se evitar a contaminação ambiental.

\section{REFERENCIAS}

ALBERTSSON, A.C.; ANDERSSON, S.O.; KARLSSON, S. The mechanism of biodegradation of polyethylene. Polymer Degradation and Stability, Essex, v.18, p.73-87. 1987.

ARAÚJO, J.A.C.; CASTELLANE, P.D. Recentes avanços da pesquisa agronômica na plasticultura brasileira. In: ARAUJO, J.A.C.; CASTELLANE, P.D. (Ed.). Dez anos de plasticultura na FCAV. Jaboticabal: FUNEP, 1996. p.67-68.

BLOUIN, J.; GUIMBERTEAU, G. Maturation et maturité des raisins. Bordeaux: Éditions Féret, 2000. $151 \mathrm{p}$.

BONORA, M.; DE CORTE, D. Additives for controlled degradation of agricultural plastics: Envirocare $^{\mathrm{TM}}$. Macromolecular Symposia, Heidelberg, v. 197, p.443-453, 2003.

BOTELHO, R.V.; PAVANELLO, A.P.; PIRES, E.J.P.; TERRA, M.M.; MÜLLER, M.M.L. Organic production of red wine grapes under plastic cover in subtropical region of Brazil. Ciência e Agrotecnologia, Lavras, v.35, n.6, p.1186-1195, 2011.

CAÑIZARES, K.A.L. A cultura do pepino. In: GOTO, R.; TIVELLI, S.W. (Ed.). Produção de hortaliças em ambiente protegido: condições subtropicais. Botucatu: UNESP, 1998. p.195-224.

CARDOSO, L. S.; BERGAMASCHI, H.; COMIRAM, F.; CHAVARRIA, G.; MARODIN, G. A. B.; DALMAGO, G. A.; SANTOS, H. P. dos ; MANDELLI, F. Padrões de interceptação de radiação solar em vinhedos com e sem cobertura plástica. Revista Brasileira de Fruticultura, Jaboticabal, v.32, n.1, p.161-171, 2010.

CASTELLANO, S.; MUGNOZZA, G.S.; RUSSO, G.; BRIASSOULIS, D.; MISTRIOTIS, A.; HEMMING, S.; WAAIJENBERG, D. Plastic nets in agriculture a general review of types and applications. Applied Engineering in Agriculture, St Joseph, v.24, n.6, p.799-808, 2008.

CHAVARRIA, G. ; CARDOSO, L. S.; BERGAMASCHI, H.; SANTOS, H. P. dos ; MANDELLI, F.; MARODIN, G. A. B. Microclima de vinhedos sob cultivo protegido. Ciência Rural, Santa Maria, v.1, p.1-6, 2009a. 
CHAVARRIA, G.; SANTOS, H. P. dos ; FIN, E.; SÔNEGO, O. R.; GARRIDO, L. da R.; MARODIN, G. A. B. Dispersão anemófila de esporangiospóros de Plasmopara viticola em cultivos protegido e convencional de videira. Revista Brasileira de Fruticultura, Jaboticabal, v.31, v. 3, p.710-717, 2009 b.

CHAVARRIA, G.; SANTOS, H.P.; SÔNEGO, O.R.; MARODIN, G.A.B.; BERGAMASCHI, H.; CARDOSO, L.S. Incidência de doenças e necessidade de controle em cultivo protegido de videira. Revista Brasileira de Fruticultura, Jaboticabal, v.29, n.3, p.477-482, 2007b.

CHAVARRIA, G.; SANTOS, H.P.; SÔNEGO, O.R.; MARODIN, G.A.B.; BERGAMASCHI, H.; CARDOSO, L.S.; SCHNEIDER, E.P. Cultivo protegido: uma alternativa na produção orgânica de videira. Revista Brasileira de Agroecologia, Bento Gonçalves, v.2, p.628-632, 2007a.

CHAVARRIA, G. ; SANTOS, H. P. dos ; ZANUS, M. C. ; MARODIN, G. A. B.; CHALAÇA, M. Z.; ZORZAN, C. Maturação de uvas Moscato Giallo sob cultivo protegido. Revista Brasileira de Fruticultura, Jaboticabal, v.32, v.1, p.151-160, 2010.

CHAVARRIA, G.; SANTOS, H. P. dos ; ZANUS, M. C.; MARODIN, G. A. B.; ZORZAN, C. Cobertura plástica sobre o vinhedo e suas influências nas características físico-químicas do mosto e do vinho. Revista Brasileira de Fruticultura, Jaboticabal, v.33, n.3, p.809-815, 2011.

COLOMBO, L.A.; ASSIS, A.M.; SATO, A.J.; TESSMANN, D.J.; GENTA, W.; ROBERTO, S.R. Out of season production of 'BRS Clara' seedless grape under protected cultivation. Ciência Rural, Santa Maria, v.41, n.2, p.212-218, 2011.

CZERMAINSKI, A.B.C.; SÔNEGO, O.R. Influência das condições climáticas sobre a eficácia de fungicidas empregados para o controle do míldio em Vitis vinifera. Ciência Rural, Santa Maria, v.34, n.1, p.5-11, 2004.

DETONI, A. M.; CLEMENTE, C.; FORNARI, C. Produtividade e qualidade da uva 'Cabernet Sauvignon' produzida sob cobertura de plástico em cultivo orgânico. Revista Brasileira de Fruticultura, Jaboticabal, v.29, n.3, p.530-534, 2007.
EDSER, C. Light manipulating additives extend opportunities for agricultural plastic films. Plastics, Additives and Compounding, Amsterdam, v.4, n.3, p.20-24. 2002.

ESPÍ, E.; SALMERÓN, A.; FONTECHA, A.; GARCÍA, Y.; REAL, A.I. Plastic films for agricultural applications. Journal of Plastic Film \& Sheeting, Rochester, v. 22, n.1, p.85-102, 2006.

FERNANDES, M.C.A. Emprego de métodos alternativos de controle de pragas e doenças na olericultura. Horticultura Brasileira, v.18, n.1, p.112-113, 2000.

FRANK, R.; BRAUN, H.E.; RITCEY, G. Disappearance of captan from field- and greenhouse-grown tomato fruit in relationship to time of harvest and amount of rainfall. Canadian Journal of Plant Science, Ottawa, v.67, n.1, p.355-357, 1987.

GENTA, W.; TESSMANN, D.J.; ROBERTO, S.R.; VIDA, J.B.; COLOMBO, L.A.; SCAPIN, C.R.; RICCE, W. da S.; CLOVIS, L.R. Manejo de míldio no cultivo protegido de videira de mesa 'BRS Clara'. Pesquisa Agropecuária Brasileira, Brasília, v.45, n.12, p.1388-1395, 2010.

GRIGOLETTI JÚNIOR, A.; SÔNEGO, O.R. Principais doenças fúngicas da videira no Brasil. Bento Gonçalves: EMBRAPA-CNPUV, 1993. 36p. (Comunicado Técnico, 17).

HALLEY, P.; RUTGERS, R.; COOMBS, S.; KETTELS, J.; GRALTON, J.; CHRISTIE, G.; JENKINS, M.; BEH H.; GRIFFIN, K,; JAYASEKARA, R., LONERGAN, G. Developing biodegradable mulch films from starch-based polymers. Starch, Weinheim, v. 53, p. 362-367, 2001.

IBGE - Instituto Brasileiro de Geografia e Estatística. Economia.2013. Disponível em: $<$ http://www.ibge. gov.br/home/estatistica/indicadores/agropecuaria/ lspa/lspa 201301.pdf. $>$. Acesso em: 2 mar. 2013.

INPEV - Instituto Nacional de Processamento de Embalagens de Agrotoxicos Vazias. Relatório Anual

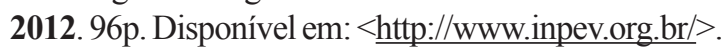
Acesso em: 28 ago. 2013.

KASIRAJAN, S.; NGOUAJIO, M. Polyethylene and biodegradable mulches for agricultural applications: A review. Agronomy for Sustainable Development, Paris, v. 32, p.501-529, 2012. 
LAFON, R.; CLERJEAU, M. Downy mildew. In: PEARSON, R.C.; GOHEEN, A.C. (Ed.). Compendium of grape diseases. Saint Paul: American Phytopathological Society, 1988. p.11-13.

LALANCETE, N.; ELLIS, M.A.; MADDEN, L.V. Estimating infection efficiency of Plasmopara viticola on grape. Plant Disease, Saint Paul, v.71, p.981-983, 1987.

LULU, J.; CASTRO, J. V.; PEDRO JUNIOR, M.J. Efeito do microclima na qualidade da uva de mesa 'Romana' (A 1105) cultivada sob cobertura plástica. Revista Brasileira de Fruticultura, Jaboticabal, v.27, n.3, p.422-425, 2005.

MENDES, C.S. Flutuação de inóculo no ar, desenvolvimento e validação de um sistema de previsão do míldio da videira. 2002. $123 \mathrm{f}$. Dissertação (Mestrado) - Universidade de Passo Fundo, Passo Fundo. 2002.

MENEGUZZO, J.; RIZZON, L.A.; MIELE, A.; AYUB, M.A.Z. Efeito de Botrytis cinerea na composição do vinho Gewürztraminer. Ciência e Tecnologia de Alimentos, Campinas, v.26, n.3, p.527-532, 2006.

MOTA, C.S.; AMARANTE, C.V.T. do; SANTOS, H.P. dos; ALBUQUERQUE, J. A. Disponibilidade hídrica, radiação solar e fotossíntese em videiras 'Cabernet Sauvignon' sob cultivo protegido. Revista Brasileira de Fruticultura, Jaboticabal, v.31, n.2, p. 432-439, 2009.

MOTA, C. S.; AMARANTE, C. V. T.; SANTOS, H. P.; ZANARDI, O. Z. Comportamento vegetativo e produtivo de videiras 'Cabernet Sauvignon' cultivadas sob cobertura plástica. Revista Brasileira de Fruticultura, Jaboticabal, v.30, n.1, p.148-153, 2008.

RANA, G.; KATERJI, N.; INTRONA, M.; HAMMAMI, A. Microclimate and plant water relationship of the "overhead" table grape vineyard managed with three covering techniques. Scientia Horticulturae, Amsterdam, v.102, p.105-120, 2004.

SANTOS, H.P.; CHAVARRIA, G. Cultivo de videira em ambiente protegido. In: CHAVARRIA, G.; SANTOS, H.P. (Ed.). Fruticultura em ambiente protegido. Brasília: Embrapa, 2012. 278p.
SANTOS, J.M.F.; OLIVEIRA, S.H.F.; DOMINGUES, R.J.; GUZZO, S.D. Avaliação da eficácia de fungicidas sistêmicos no controle da ferrugem ( $\mathrm{He}$ mileia vastatrix $\mathrm{L}$.) do cafeeiro, sob chuva simulada. Arquivos do Instituto Biológico de São Paulo, São Paulo, v.69, n.1, p.45-49, 2002.

SAUTOUR, M.; DANTIGNY, P.; DIVIES, C.; BENSOUSSAN, M. A temperature-type model for describing the relationship between fungal growth and water activity. International Journal of Food Microbiology, Amsterdam, v.67, n.1-2, p.63-69, 2001.

SÔNEGO, O.R.; GARRIDO, L. da R.; GRIGOLETTI JÚNIOR, APrincipais doenças fúngicas da videira no Sul do Brasil. Bento Gonçalves: Embrapa Uva e Vinho, 2005. 32p. (Circular Técnica, 56)

TONietto, J.; MANDELli, F. Clima. Regiões vitivinícolas Brasileiras. In: Uvas para processamento. Brasília: Embrapa Informação Tecnológica, 2003. 134p. (Frutas do Brasil, 34).

VIDA, J.B.; ZAMBOLIM, L.; TESSMANN, D.J.; BRANDÃO FILHO, J.U.T.; VERZIGNASSI, J.R.; CAIXETA, M.P. Manejo de doenças de plantas em cultivo protegido. Fitopatologia Brasileira, Brasília, n.29, p.355-372, 2004.

YAMAMOTO, L.Y.; ASSIS, A.M.; MORAIS, H.; SOUZA, F.S.; SCAPIN, C.R.; TESSMANN, D.J.; SOUZA, R.T.; ROBERTO, S.R. Production and physico-chemical characteristics of bunches of 'BRS Clara' grapevine under plastic cover and plastic screen grown out of season. Revista Brasileira de Fruticultura, Jaboticabal, v.34, n.1, p.160-166, 2012.

YU, J.; LI, H.; ZHANG, M.; ZHANG, M. Study on Degradation Mechanism of Polyethylene Films Containing Additives with Metal Ions at a Simulated Composting Temperature. Journal of Applied Polymer Science, New York, v. 75, p.523-527, 2000.

ZANTARIM, M.; CARDOSO, A.I.I.; FURTADO, E.L. Efeito de tipos de leite sobre oídio em abóbora plantadas a campo. Horticultura Brasileira, Brasília, v.23, n.2, p.198-201, 2005. 